\title{
Pneumatic Proportional Valve With Piezoelectric ACtuator
}

\author{
AVRAM, M.; BUCSAN, C.; DUMINICA, D.; \\ BOGATU, L. \& SPANU, A.R.
}

\begin{abstract}
The paper deals with a pneumatic proportional valve with a piezoelectric actuator developed by the authors. The experimental model, a pneumatic positioning system based on the new proportional equipment and the control algorithm are considered. The tests performed with the presented positioning system revealed that it is possible to obtain a positioning accuracy of $\pm 0.3 \mathrm{~mm}$.
\end{abstract}

Key words: proportional valve, piezoelectric actuator, positioning system
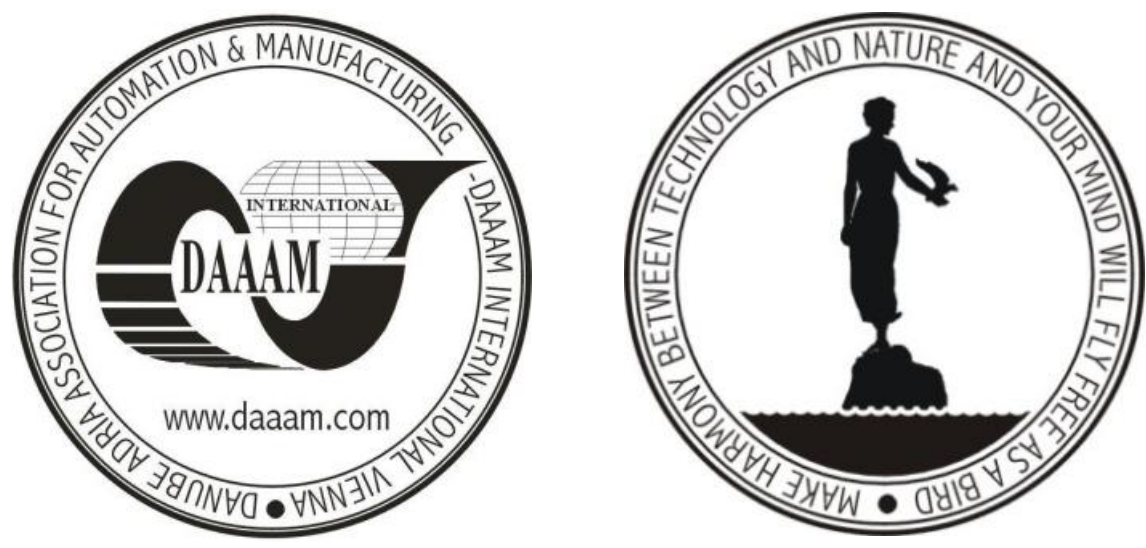

Authors' data: Univ.Prof. Dipl.-Eng. Ph.D. Avram, M[ihai]; Univ.Prof. Dipl.-Eng. Ph.D. Bucsan, C[onstantin]; Dipl.-Eng. Ph.D. Duminica, D[espina]; Lecturer Dipl.Eng. Ph.D. Bogatu, L[ucian]; Lecturer Dipl.-Eng. Ph.D. Spanu, A[lina] R[odica], Politehnica University of Bucharest, Mechatronics and Precision Mechanics Department, mavram02@yahoo.com

This Publication has to be referred as: Avram, M[ihai]; Bucsan, C[onstantin]; Duminica, D[espina]; Bogatu, L[ucian] \& Spanu, A[lina] R[odica] (2011). Pneumatic Proportional Valve with Piezoelectric Actuator, Chapter 27 in DAAAM International Scientific Book 2011, pp. 331-346, B. Katalinic (Ed.), Published by DAAAM International, ISBN 978-3-901509-84-1, ISSN 1726-9687, Vienna, Austria

DOI: $10.2507 /$ daaam.scibook.2011.27 
Avram, M.; Bucsan, C.; Duminica, D.; Bogatu, L. \& Spanu, A.R.: Pneumatic Prop...

\section{Introduction}

In Pneumatics, the resistive method - modifying a local flowing area - is used to adjust the flow. That is achieved using valves mounted in the circuits whose flow must be controlled. The adjustment of the flowing area is obtained by positioning a mobile element in respect to a fix seat machined in the body of the device. There is a large constructive variety of valves characterized by the following: the shape of the seat and of the mobile element, the type of the movement between them, the adjustment method (Belforte et al., 1998, Pashkov et al., 2004). In the case of proportional valves, the adjustment is made using an actuator, that is the interface between the electronic control unit and the pneumatic power unit. In most cases the actuator is a proportional electro-magnet. A pertinent analysis of the actual trends of the pneumatic equipment domain reveals sustained researches in order to integrate another types of actuators - generically known as "unconventional" - in their structure (Avram, 2005). The goal is to improve the static and dynamic performances of the devices and to miniaturize their sizes. The unconventional actuators category includes: piezoelectric actuators, magneto-strictive actuators, actuators without mobile elements.

The paper deals with a pneumatic proportional valve with a piezoelectric actuator. There are presented:

- the experimental model;

- a pneumatic positioning system based on the new proportional equipment;

- the control algorithm;

- the experimental results.

\section{The experimental model}

Figure 1 shows the principle scheme of the experimental model. There are two subassemblies: the actuator $A$ and the base module $M B$.

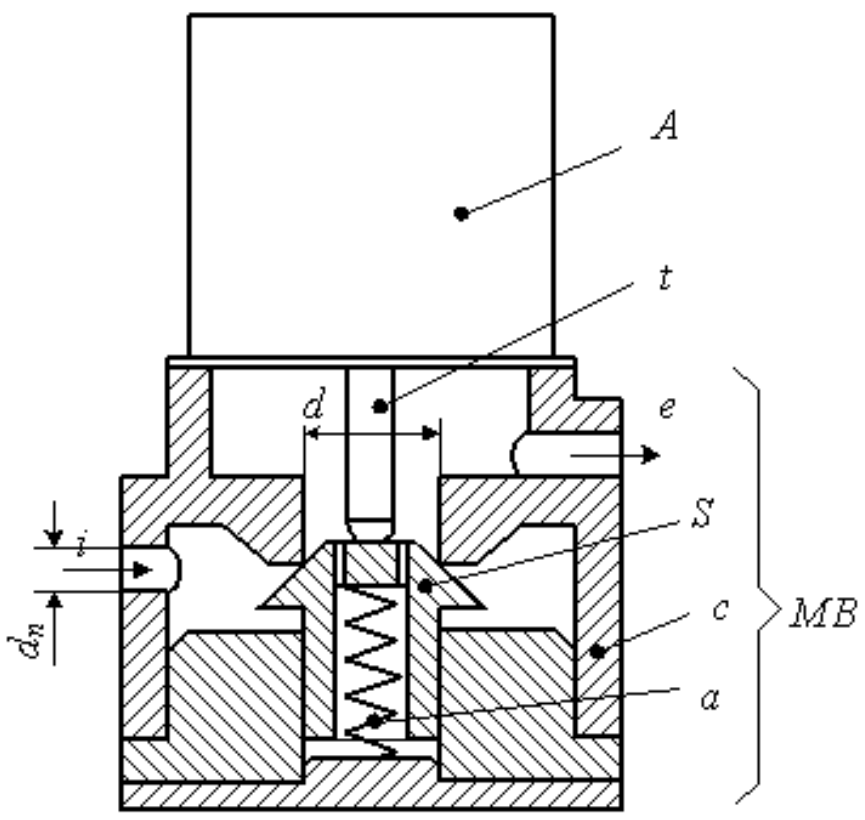

Fig. 1. The principle scheme of the experimental model. 
The control of the flowing area is assured by a conical equilibrated valve $S$, whose position in respect to the seat machined in the body $c$ is determined by the value of the $A$ actuator power voltage. In order to choose the proper actuator, the conical valve was dimensioned and the resisting force was calculated. The input data were the following:

- the maximum control flow: $q_{\max }=100 \mathrm{l} / \mathrm{min}$;

- the supply pressure: $P_{a}=10 \mathrm{bar}$;

- the seat diameter: $d=8 \mathrm{~mm}$;

- the nominal diameter: $d_{n}=2 \mathrm{~mm}$.

The results obtained are the following:

- the maximum displacement: $x_{n}=0.125 \mathrm{~mm}$;

- the maximum resisting force: $F_{r e z} \approx 10 N$, and this data were used to choose the actuator.

The piezoelectric actuator is based on the piezoelectric effect that consists in the variations of the dimensions of a body subjected to an electric voltage. The response of such an actuator is almost instantaneous, the positioning is continuous, unwanted effects like wearing are not present, the dimensions are small and the output forces are very high. Among the disadvantages of such an actuator can be mentioned the small working stroke, of about 1/1000 of its size on the deformation direction. In order to generate the stroke previously computed, the piezoelectric actuator would have a length of about $200 \mathrm{~mm}$. This was the main reason for finding a constructive solution that would allow miniaturization.

A first approach was the use of a classical piezo-ceramic stack whose displacement was hydraulically amplified. The model P-010-20, manufactured by Physik Instrumente, was chosen due to the fact that was able to deliver a maximum displacement of $30 \mu \mathrm{m}$ for a supply voltage of $1000 \mathrm{~V}$ (www.physikinstrumente.com). The overall sizes of the piezo element are: diameter $D=10 \mathrm{~mm}$ and length $L=30 \mathrm{~mm}$.

The principle scheme of the subassembly built by the authors is presented in figure 2 .

The displacement of the piezo-electric actuator 1 is amplified by a hydraulic amplifier consisting of a piston 2 and a plunger 3, separated by the working fluid that exists in the volume $V$. The piezo-electric stack must be pre-compressed using a specially designed system. The subassembly must also provide the adjustment of the zero position.

If the volume $V$ is completely filled with the working fluid and there are no exterior leaks, the displacement $x$ of the output element of the actuator - plunger 3 will be:

$$
x=k_{A} \cdot x_{A}
$$

where $x_{A}$ is the displacement of the actuator 1 and $k_{A}$ is the gain, given by: 


$$
k_{A}=(D / d)^{2}
$$

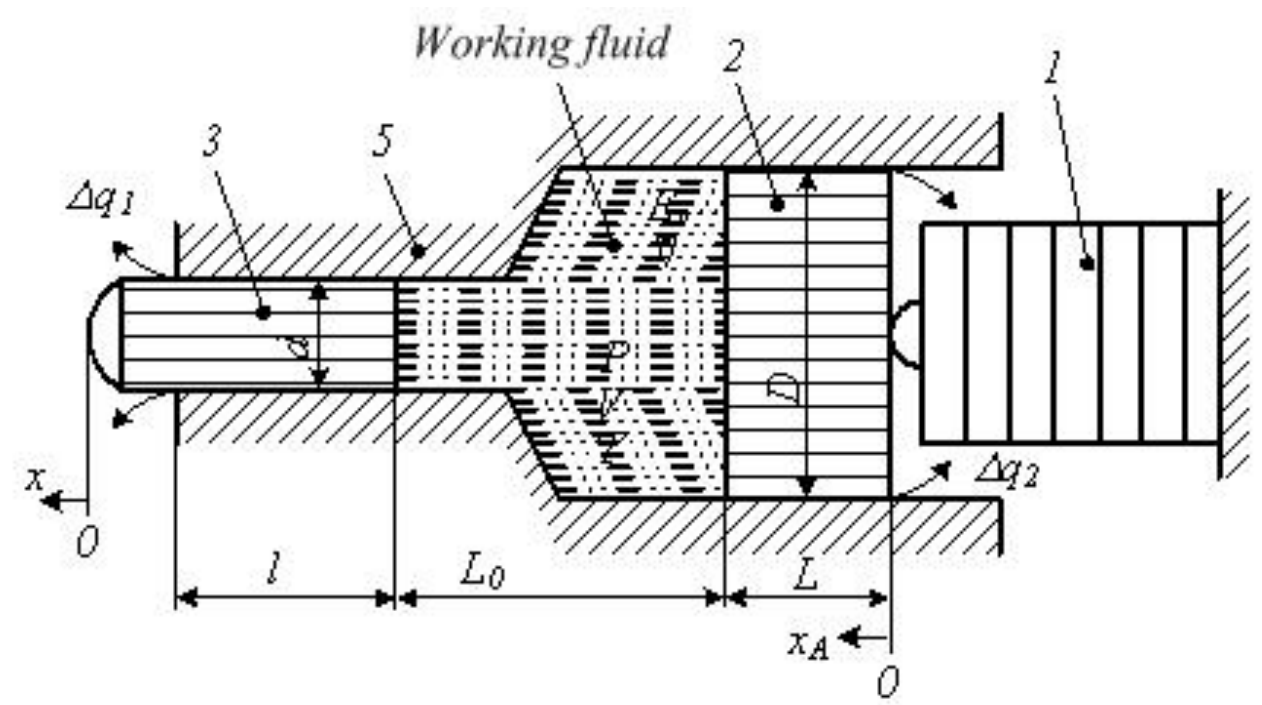

Fig. 2. The principle scheme of the subassembly that uses a classic piezo-ceramic stack.

The following values were adopted for the built experimental model: $d=$ $10 \mathrm{~mm}, D=40 \mathrm{~mm}, l=10 \mathrm{~mm}$ and $L=20 \mathrm{~mm}$, leading to a gain $k_{A}=16[-]$. For a maximum displacement $x_{A, \max }=30 \mu \mathrm{m}$ of the actuator 1 an output displacement $x=$ $0.48 \mathrm{~mm}$ is obtained, a proper value for the aimed application.

The physical model built by the authors is presented in figure 3 .

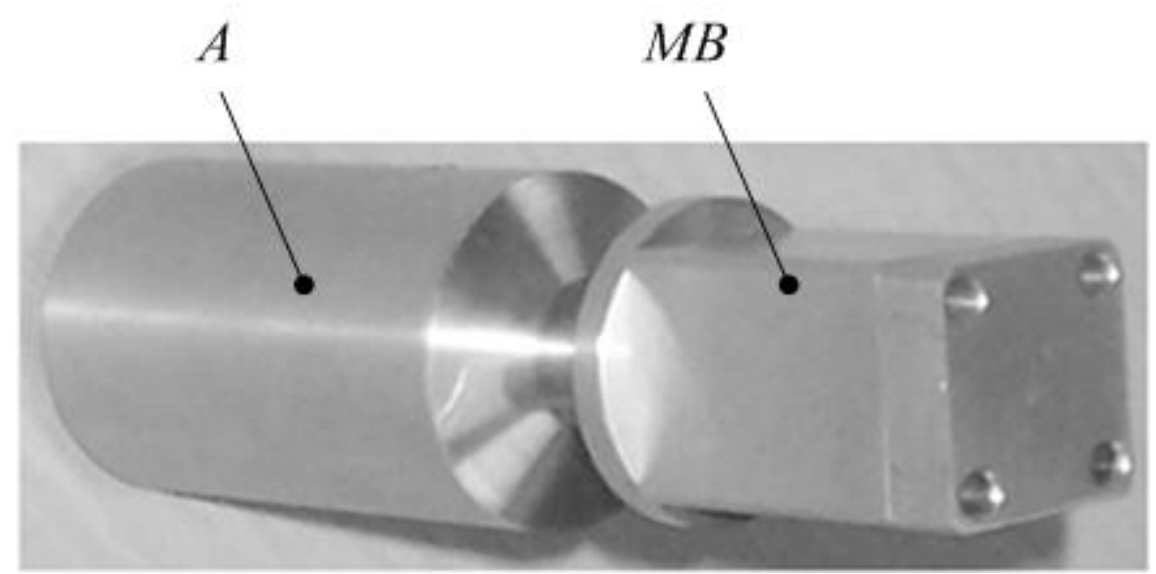

Fig. 3. The physical model.

The tests performed on the experimental model led to the following conclusions:

a. The flow losses from the working volume directly affect actuator accuracy. These losses can be removed by correct clearance dimensioning and by the choice of a high viscosity fluid.

b. Though a high viscosity fluid is used, the probability of losses through the clearances between the piston 2 and its bore or between the plunger 3 and its bore is 
still present. These losses directly affect the accuracy of the equipment. Reducing the clearances is not an option, because leads to the significant increase of the equipment price. A feasible solution involves higher clearances $j=8 \ldots 10 \mu \mathrm{m}$ and the use of nonmetallic seals.

c. The volume must be completely filled and the fluid volume must be preserved over time. Air entrance in the working volume is not accepted.

Another version of the constructive solution uses a P-287 piezo-electric actuator featuring internal mechanical amplification, manufactured by Physik Instrumente. The maximum output displacement of the actuator is $700 \mu \mathrm{m}$ and the force developed by the unloaded actuator is $80 \mathrm{~N}$.

Figure 4 presents the 3D model of the solution that integrates the $P-287$ actuator. Figure 5 presents two physical implementations of the previous design, built and experimentally tested (Avram et al., 2008). The model presented in figure 5,b) includes two supplementary sensors: a displacement sensor $T_{p o z}$ and a force sensor $T_{F}$.

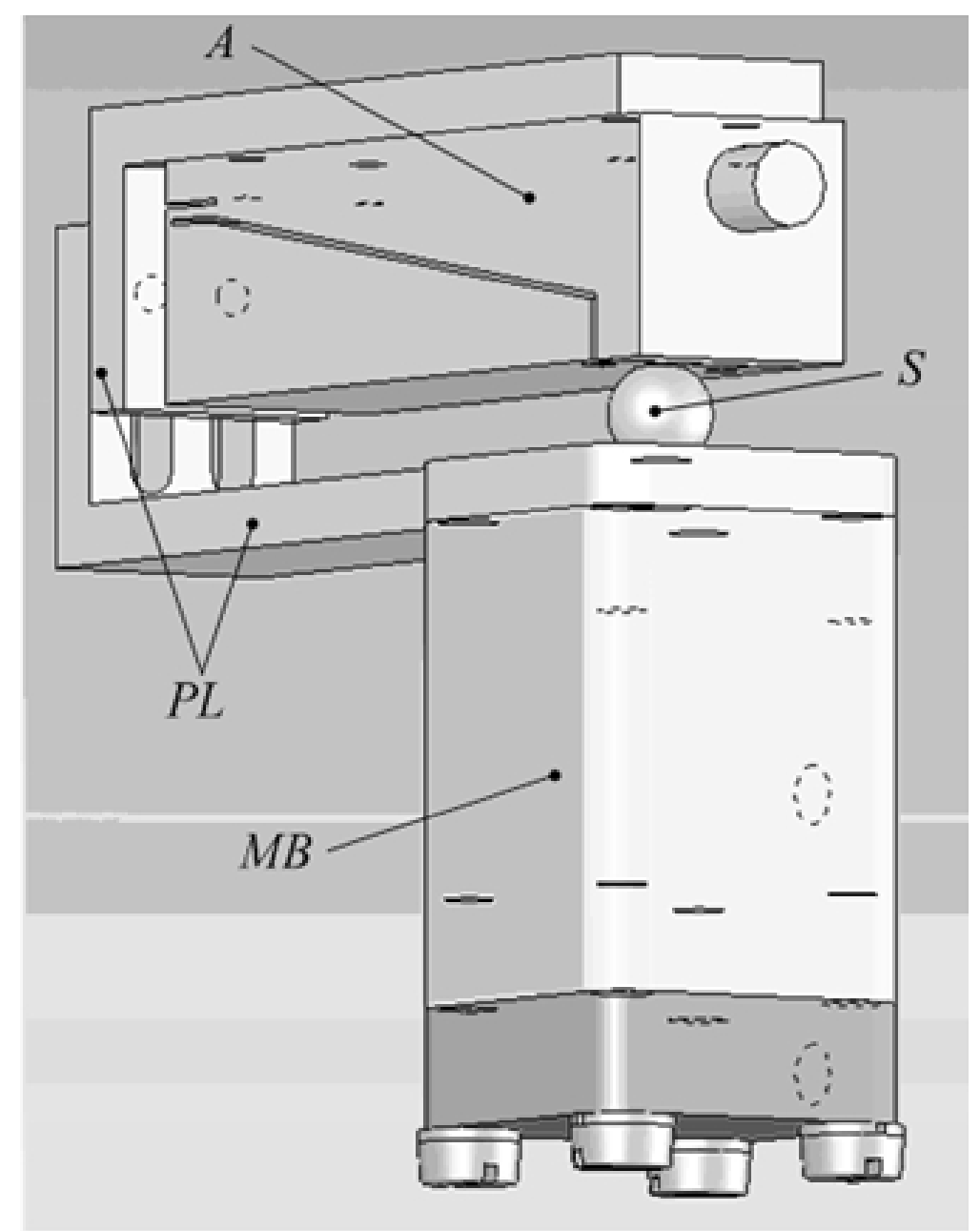

Fig. 4. The 3D model of the solution that integrates the P-287 actuator.

The experimental setup presented in figure 6 was designed and built in order to establish the characteristic flow rate - control voltage.

The following elements can be identified: 
Avram, M.; Bucsan, C.; Duminica, D.; Bogatu, L. \& Spanu, A.R.: Pneumatic Prop...

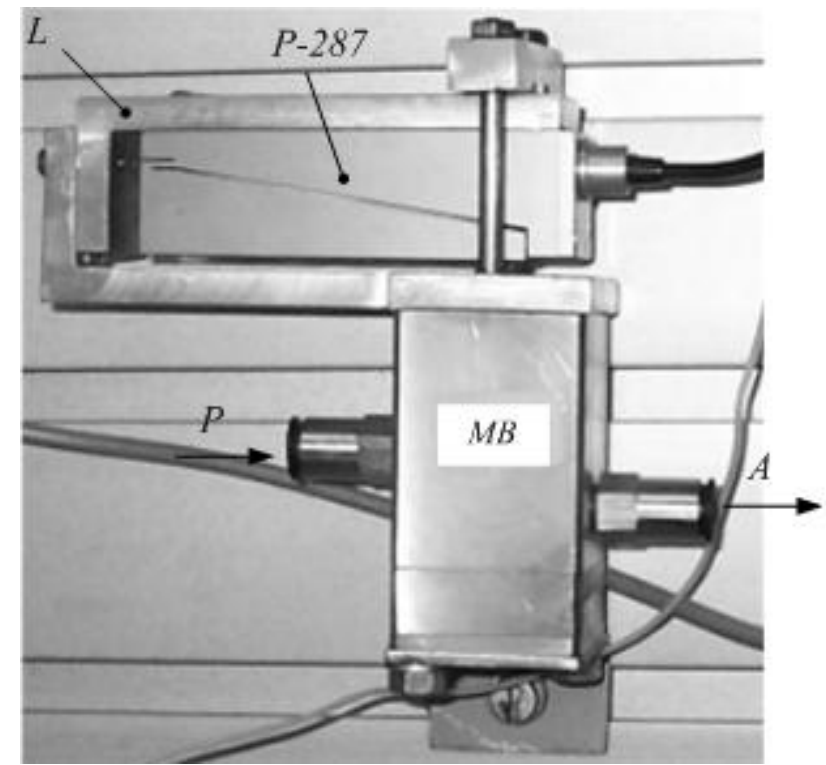

a)

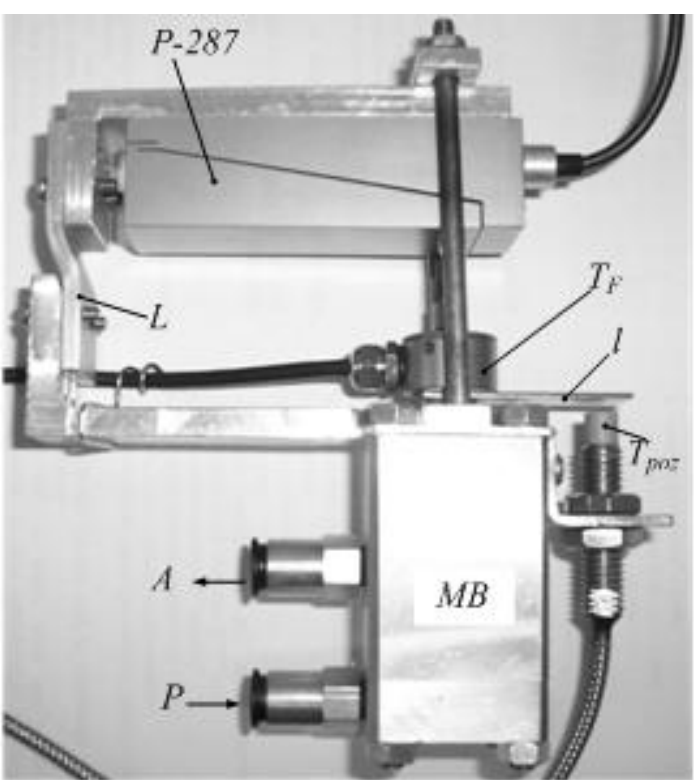

b)

Fig. 5. Two physical implementation of the solution that integrates the P-287 actuator: a) the first experimental model; b) the second experimental model, that features a displacement sensor $T_{p o z}$ and a force sensor $T_{F}$.

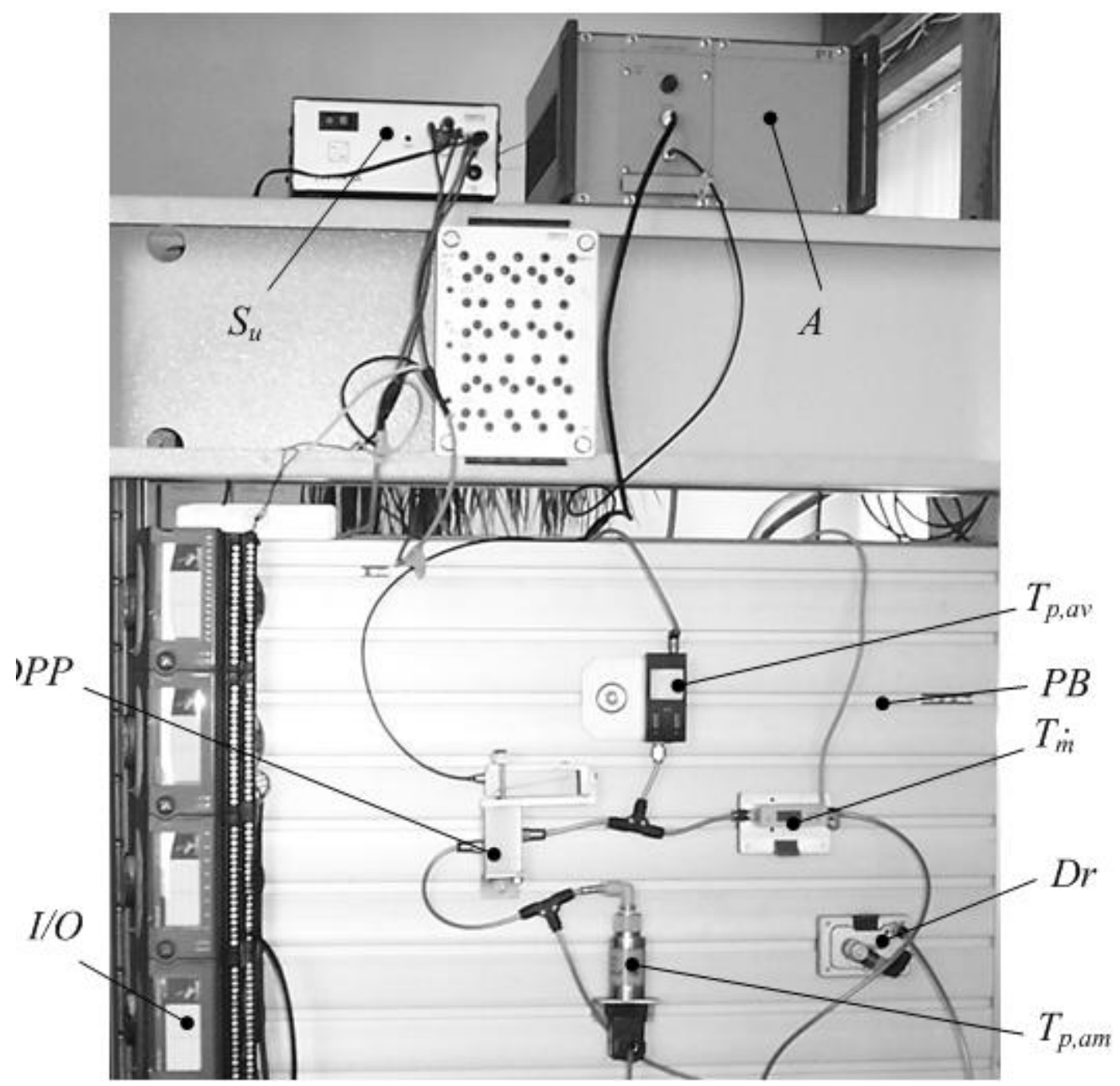

Fig. 6. The experimental setup. 
- experimental model of the designed and built pneumatic proportional valve $D P P$;

- pressure sensors $T_{p, a v}$ and $T_{p, a m}$, that measure pressures upstream and downstream the valve;

- flow rate sensor $T_{m}$ that measures the flow rate through the equipment;

- manually operated pneumatic throttle $D r$;

- FieldPoint I/O modules;

- high voltage amplifier, adjustable in the range of $0 \ldots 1000 \mathrm{~V}$, used for the supply of the piezoelectric converter;

- low voltage (24V) supply required for the supply of sensors;

- base plate $P B$ which supports the whole assembly;

- $P C$ (not presented) that communicates with I/O modules via the serial port RS 232; the programming environment LabVIEW 7.1 is installed on the PC.

The interface between the personal computer and the pneumatic positioning unit is achieved through a modular acquisition and control system - FieldPOINT, manufactured by National Instruments (www.fieldpoint.net). The connection between the PC and the FieldPOINT modules is made through a serial interface RS232. In order to have a fully functional setup, an application software was developed using LabView programming environment.

The diagram flow rate-control voltage for the model in figure 5 , a, experimentally established, is presented in figure 7.

Hysteresis diagram

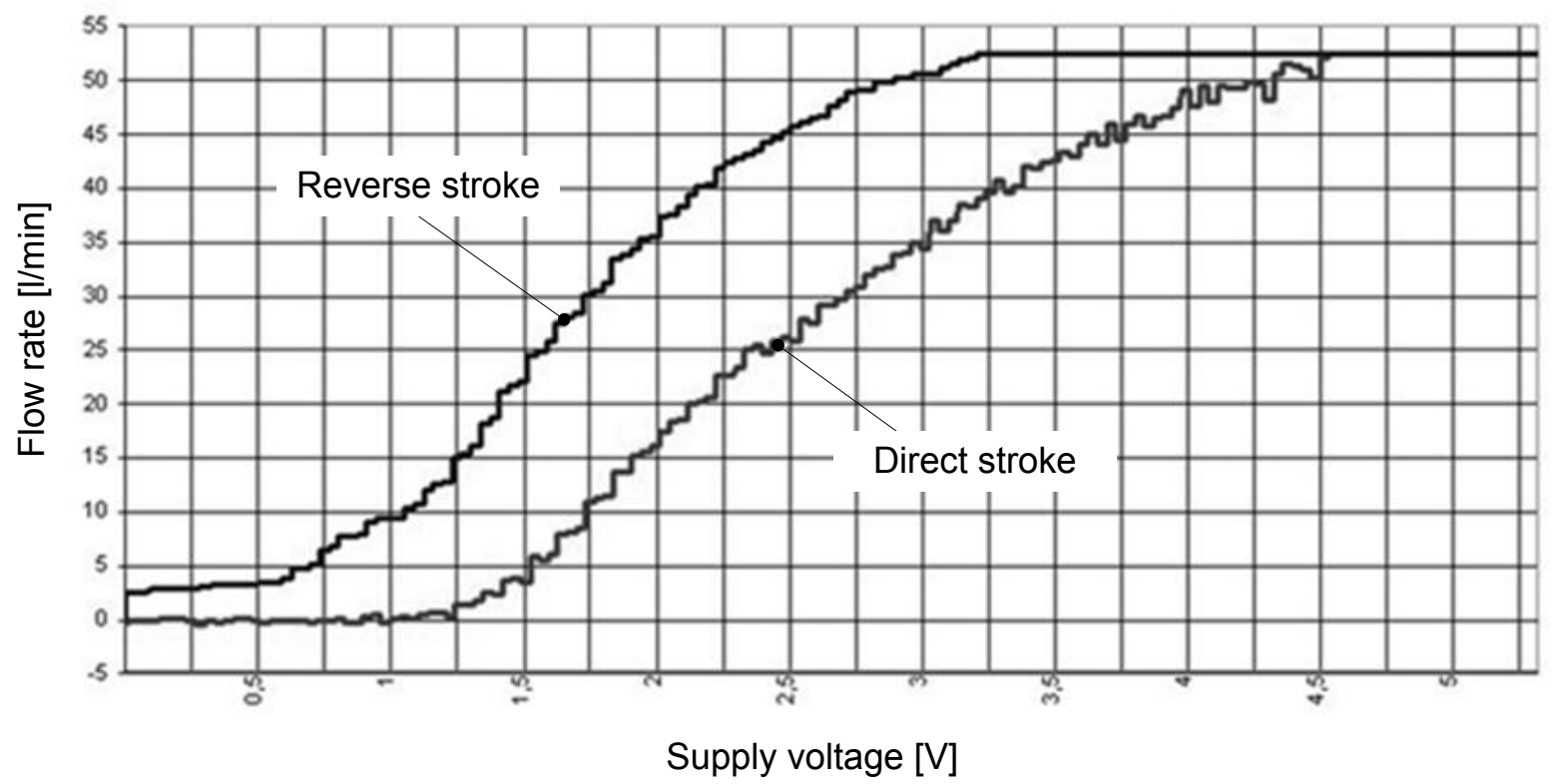

Fig. 7. The diagram flow rate-control voltage for the model in figure 5, a.

A significant hysteresis can be noticed. A frequently used method for hysteresis reduction involves the existence of a position feedback that would allow the continuous tracking of the valve position. If the obtained opening is not the needed one, the control voltage is modified in real time. That is why a first stage of optimization of the proportional equipment involved a capacitive position sensor $T_{p o z}$ (fig.5, b). the structure was further completed with a piezoelectric force sensor $T_{F}$ that measures the force needed to open the valve. 
Avram, M.; Bucsan, C.; Duminica, D.; Bogatu, L. \& Spanu, A.R.: Pneumatic Prop...

\section{The pneumatic positioning system}

Figure 8 presents the working scheme of a pneumatic positioning system that integrates two proportional valves $D P P \_1$ and $D P P \_2$ of the type described above. The scheme also features the following equipment:

- a linear pneumatic motor $M P L$;

- a position transducer $T_{p}$;

- two one-way valves $S d \_l$ and $S d \_2$, unlockable, pneumatic controlled;

- two one-way valves $S s_{-} l$ and $S s_{-} 2$;

- two classic pneumatic direction control valves, $D C 3 / 2$ and $D C 5 / 3$.

The currently presented system works in a closed loop. The position of the load is permanently tracked by the position transducer $T_{p}$ and compared to the position programmed by the electronic control system (not shown). The mobile assembly will move until the two values are equal. Using such a system, the load can be positioned in any point on the working area, the programmed positions being very close. The accuracy depends on the resolution of the position transducer.

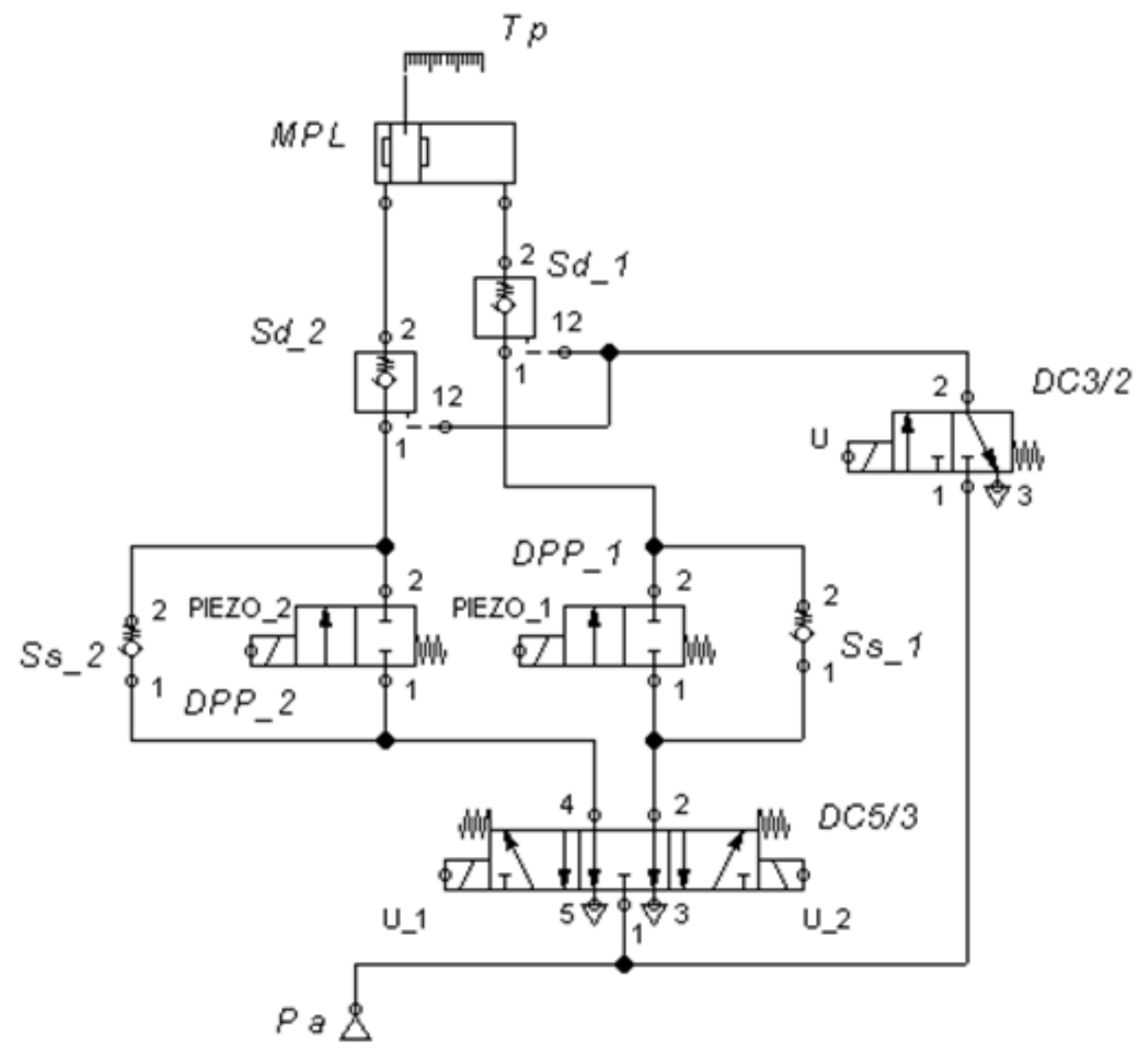

Fig. 8. The working scheme of the pneumatic positioning system.

The system has been provided with two directional valves $S_{d 1}$ and $S_{d 2}$, unlockable, air driven, one for each motor circuit; this manner a firmly closing of the 
two active chambers of the motor is assured when the programmed position has been reached.

The eventual leaks that can appear at the level of the two proportional equipment in this situation will not influence the position of the load.

The obtained experimental model is shown in figure 9. The component equipment in the structure of the experimental setup can be identified in correspondence to figure 3 .

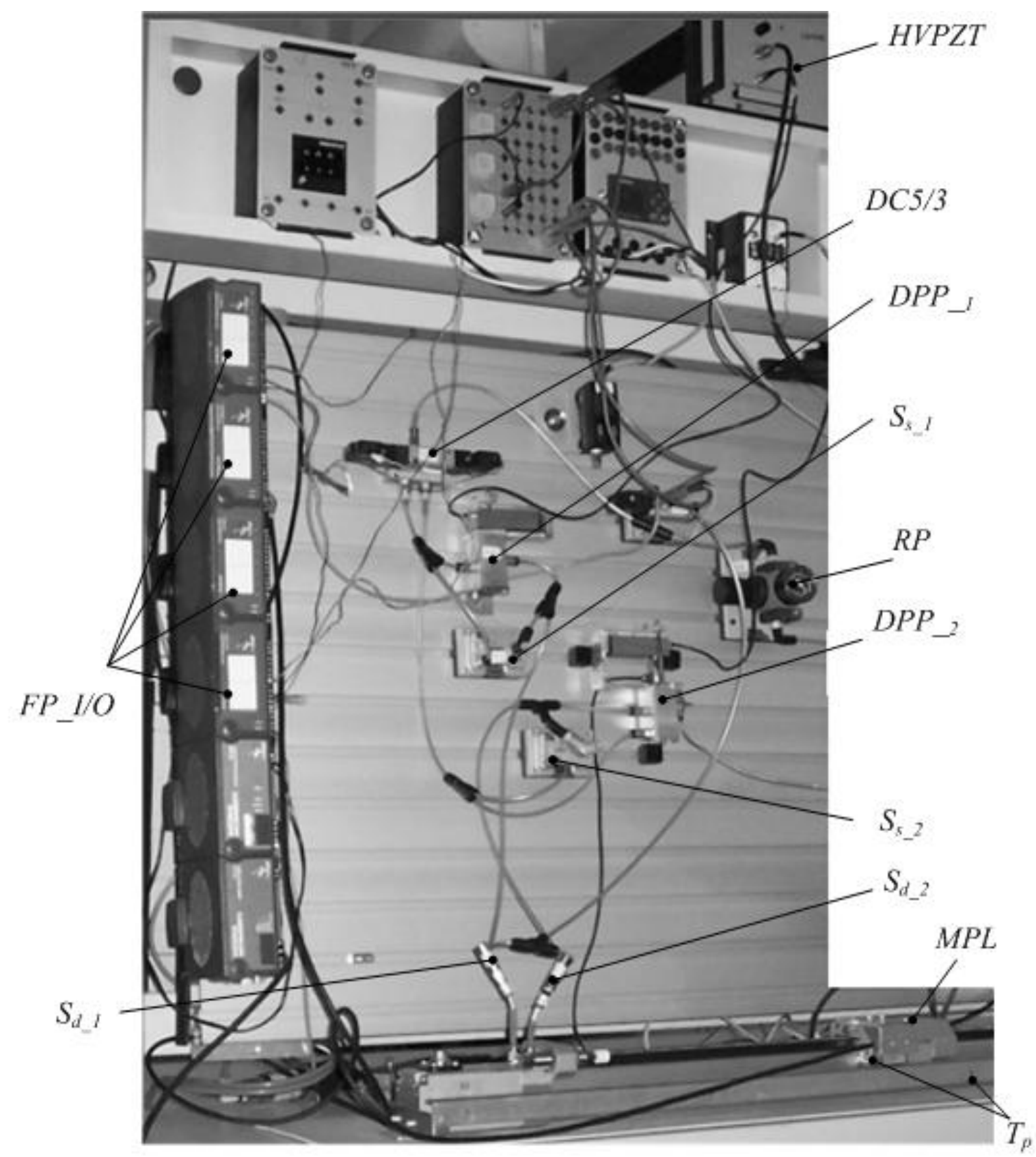

Fig. 9. The experimental model.

A linear measurement system LIMES L1 (fig.10, a) manufactured by Kübler was chosen for position control. The system is equipped with a magnetic sensor whose measuring principle is presented in figure $10, \mathrm{~b}$. The obtained output signals vary according to figure $10, \mathrm{c}$. 


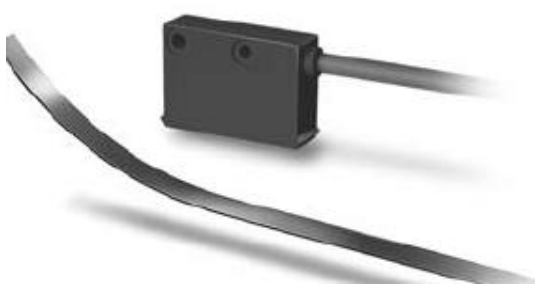

a)

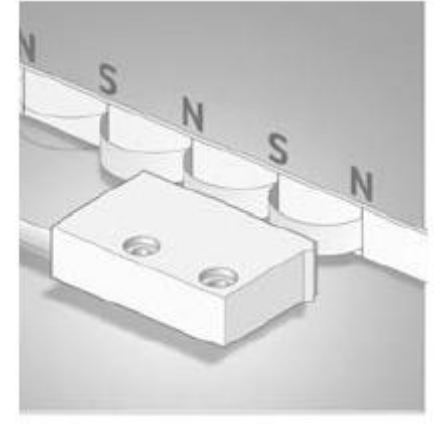

b)

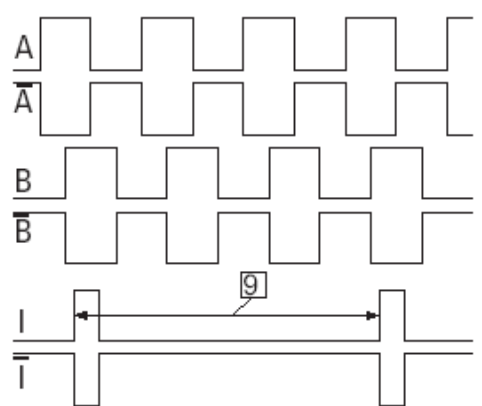

c)

Fig. 10. The linear measuring system LIMES L1: a) a view of the sensor; b) the measuring principle; c) the output signals.

To electrically connect this measurement system, the 0 axis of a $F P-Q U A D$ 510 module was used. This module allows the connection of four measurement axes, numbered from 0 to 3 , as shown in table 1 .

\begin{tabular}{|c|c|c|c|c|}
\hline Signal & Axis 0 & Axis 1 & Axis 2 & Axis 3 \\
\hline$+\mathrm{A}$ & 1 & 5 & 9 & 13 \\
\hline -A & 17 & 21 & 25 & 29 \\
\hline$+\mathrm{B}$ & 2 & 6 & 10 & 14 \\
\hline -B & 18 & 22 & 26 & 30 \\
\hline$+\mathrm{I}$ & 3 & 7 & 11 & 15 \\
\hline -I & 19 & 23 & 27 & 31 \\
\hline $\mathrm{V}_{\text {SUP }}$ & 4 & 8 & 12 & 16 \\
\hline COM & 20 & 24 & 28 & 32 \\
\hline
\end{tabular}

Tab. 1. FP-QUAD-510 module connections.

In order to control the two proportional pneumatic valves $D P P \_1$ and $D P P \_2$, two voltages: $u_{P I E Z O_{-} I}$ and $u_{P I E Z O_{-} 2}$ must be generated in the range of $0 \ldots 10 \mathrm{~V}$. These voltage levels are the command signals for the HVPZT amplifiers supplying the two $P$-287 piezoelectric converters integrated in the construction of the proportional valves. The FP-AO-210 module was selected for this purpose. This module features eight analogue voltage outputs, software configurable. The eight channels are able to deliver voltages in the range of $0 \ldots 10 \mathrm{~V}$. The channels 0 and 1 are used for the present case, as shown in table 2.

\section{The control algorithm}

The movement of the load can be produced in two opposite directions. Therefore, a direction coefficient $s$ was introduced:

$$
s=\left\{\begin{array}{l}
1 \text { if the movement is from the right to the left } \\
0 \text { if the movement is from the left to the right }
\end{array}\right.
$$




\begin{tabular}{|c|c|c|c|}
\hline \multirow{2}{*}{ Channel } & \multicolumn{3}{|c|}{ Connector number } \\
\cline { 2 - 4 } & $\begin{array}{c}V_{\text {out }} \\
\text { output voltage }\end{array}$ & $\begin{array}{c}\text { COM } \\
\text { ground }\end{array}$ & $\begin{array}{c}V_{\text {sup }} \\
\text { voltage supply }\end{array}$ \\
\hline 0 & 1 & 2,18 & 17 \\
\hline 1 & 3 & 4,20 & 19 \\
\hline 2 & 5 & 6,22 & 21 \\
\hline 3 & 7 & 8,24 & 23 \\
\hline 4 & 9 & 10,26 & 25 \\
\hline 5 & 11 & 12,28 & 27 \\
\hline 6 & 13 & 14,30 & 29 \\
\hline 7 & 15 & 16,32 & 31 \\
\hline
\end{tabular}

Tab. 2. The FP-AO-210 module connections.

Figure 11 shows the waveforms of the control voltages $u_{-1}, u_{-2}, u, u_{\text {Piezo_l }}$ and $u_{\text {Piezo_2 }}$ (figure 8) depending on the position of the load $y$.

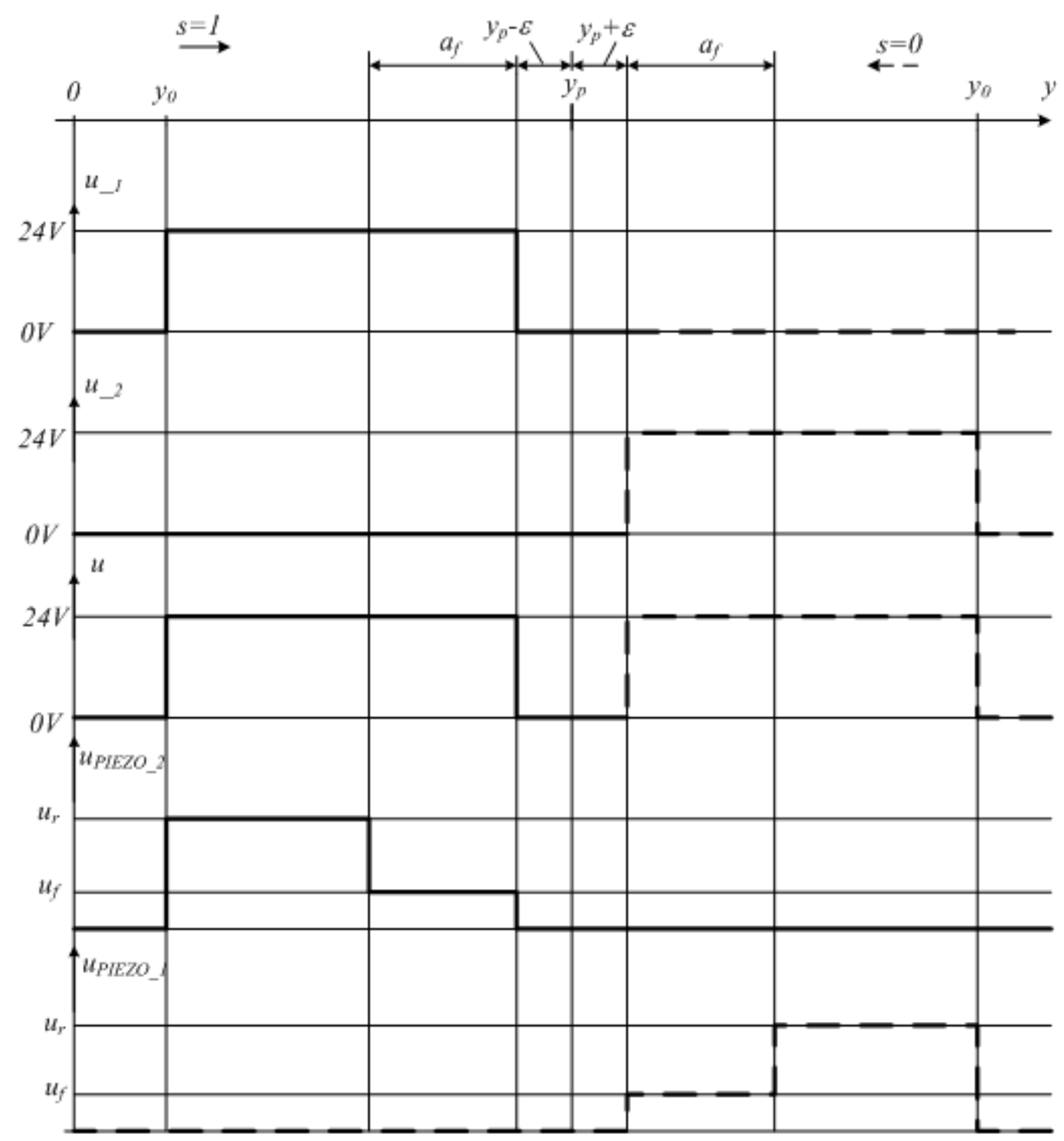

Fig. 11. Control voltage waveforms. 
Avram, M.; Bucsan, C.; Duminica, D.; Bogatu, L. \& Spanu, A.R.: Pneumatic Prop...

In the braking zone (situated at the distance $a_{f}$ in respect with the final target position $y_{p}$ ) the voltages on the two piezoelectric actuators $u_{\text {Piezo_ } 1}$ and $u_{\text {Piezo_ } 2}$ are reduced to the braking value $u_{f}$. So, the speed of the load decreases in the proximity of the target, that is favourable for an accurate positioning. The values $a_{f}, u_{r}$ and $u_{f}$ are set by the operator after some testing trials.

The positioning subroutine was written using the notations in figure 11 and the analytical relations presented in table 3 .

The notations have the following meanings:

- $y_{0}$ - the initial position;

- $y_{p}$ - the final target position;

- $a_{f}$-the braking distance;

- $\varepsilon$ - the positioning accuracy;

- $u_{r}$ - the working phase voltage value;

- $u_{f}$-the braking phase voltage value.

\begin{tabular}{|c|c|c|c|}
\hline \multicolumn{2}{|c|}{ Movement to the right: $y_{0}<y_{P}(s=1)$} & \multicolumn{2}{|c|}{ Movement to the left: $y_{0}>y_{P}(s=0)$} \\
\hline Initial stage: & $\left\{\begin{array}{l}u_{-1}=24 \mathrm{~V} \\
u_{2}=0 \mathrm{~V} \\
u^{2}=24 \mathrm{~V}\end{array}\right.$ & Initial stage: & $\left\{\begin{array}{l}u_{-1}=0 \mathrm{~V} \\
u_{2}=24 \mathrm{~V} \\
{ }_{-}-24 \mathrm{~V}\end{array}\right.$ \\
\hline Case 1: & 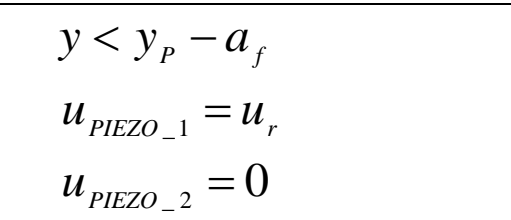 & Case 1: & $\begin{array}{l}y>y_{P}+a_{f} \\
u_{P_{P E Z O_{-} 2}}=u_{r} \\
u_{\text {PIEZO_ }_{1}}=0\end{array}$ \\
\hline Case 2: & $\begin{array}{l}y_{p}-a_{f} \leq y<y_{P}-\varepsilon \\
u_{\text {PIEZO_-1 }_{-}}=u_{f} \\
u_{\text {PIEZO_- }_{-2}}=0\end{array}$ & Case 2: & $\begin{array}{c}y_{P}+a_{f} \geq y>y_{P}+\varepsilon \\
u_{\text {PIEZO_ } 2_{-}}=u_{r} \\
u_{\text {PIEZO_- }_{1}=0}\end{array}$ \\
\hline Case 3: & $\begin{array}{l}y_{p}-\varepsilon \leq y \leq y_{P}+\varepsilon \\
\left\{\begin{array}{l}u_{-1}=0 V \\
u_{-2}=0 V \\
u=0 V \\
u_{\text {PIEZO_1 }_{-1}=0 V}\end{array}\right. \\
u_{\text {PIEZO_- }_{2}=0}\end{array}$ & Case 3: & $\begin{array}{l}y_{p}+\varepsilon \geq y \geq y_{P}-\varepsilon \\
\left\{\begin{array}{l}u_{-1}=0 V \\
u_{-2}=0 V \\
u=0 V \\
u_{\text {PIEZO_- }_{-2}=0 V} \\
u_{P_{I E Z O_{-} 1}=0}\end{array}\right.\end{array}$ \\
\hline
\end{tabular}

Tab. 3. The analytical relations for the positioning subroutine.

An application software based on this algorithm was developed using the LabView programming environment. The main panel of the application is shown in figure 12 and the programming diagram is shown in figure 13. 


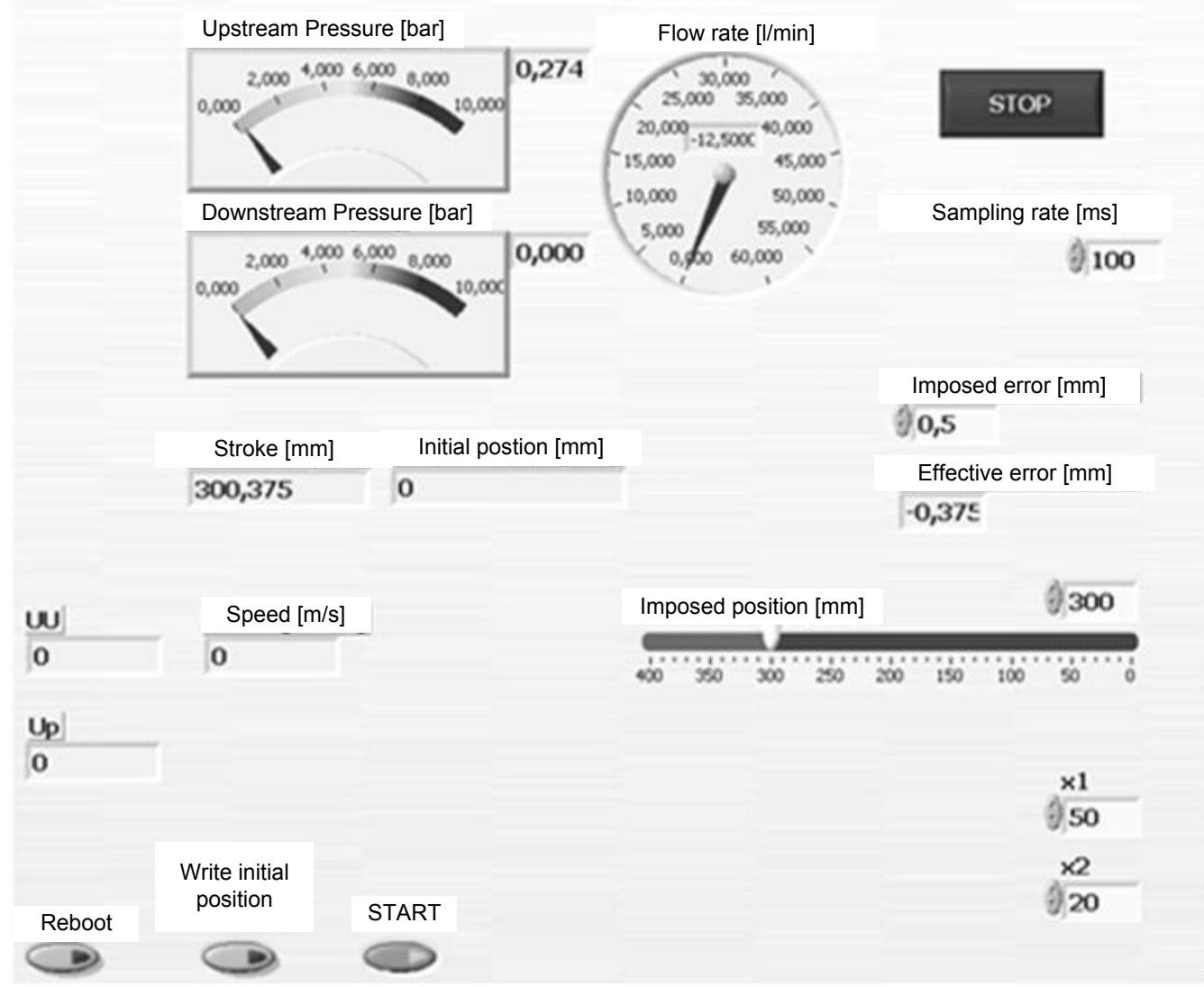

Fig. 12. Main panel of the application.

\section{Experimental results}

The steps required for an experimental testing session are the following:

- powering up the I/O FieldPoint modules and the transducers (24VDC);

- powering up the amplifier that drives the piezoelectric actuator integrated into the proportional pneumatic equipment (220VAC);

- turning on the air compressor and setting the desired supply air pressure;

- launching the application software.

A first set of measurements was achieved by running the program and performing the data acquisition. The air power supply has been already set to $P_{a}=4$ bar. When the program is launched the data acquisition starts, and the indicators will provide the real time values of the monitored parameters.

The second set of measurements was intended to provide the dynamic behaviour of the mechatronic unit. The following parameters were measured:

- the positioning accuracy;

- the repeatability of the system;

- the dynamic working of the positioning system.

The testing parameters were the following:

- zero resisting force, $F_{r}=0$;

- the supply pressure $P_{a}=4 \mathrm{bar}$;

- the working voltage $u_{r}=10 \mathrm{~V}$; 
Avram, M.; Bucsan, C.; Duminica, D.; Bogatu, L. \& Spanu, A.R.: Pneumatic Prop...

- the braking voltage $u_{f}=2 \mathrm{~V}$.

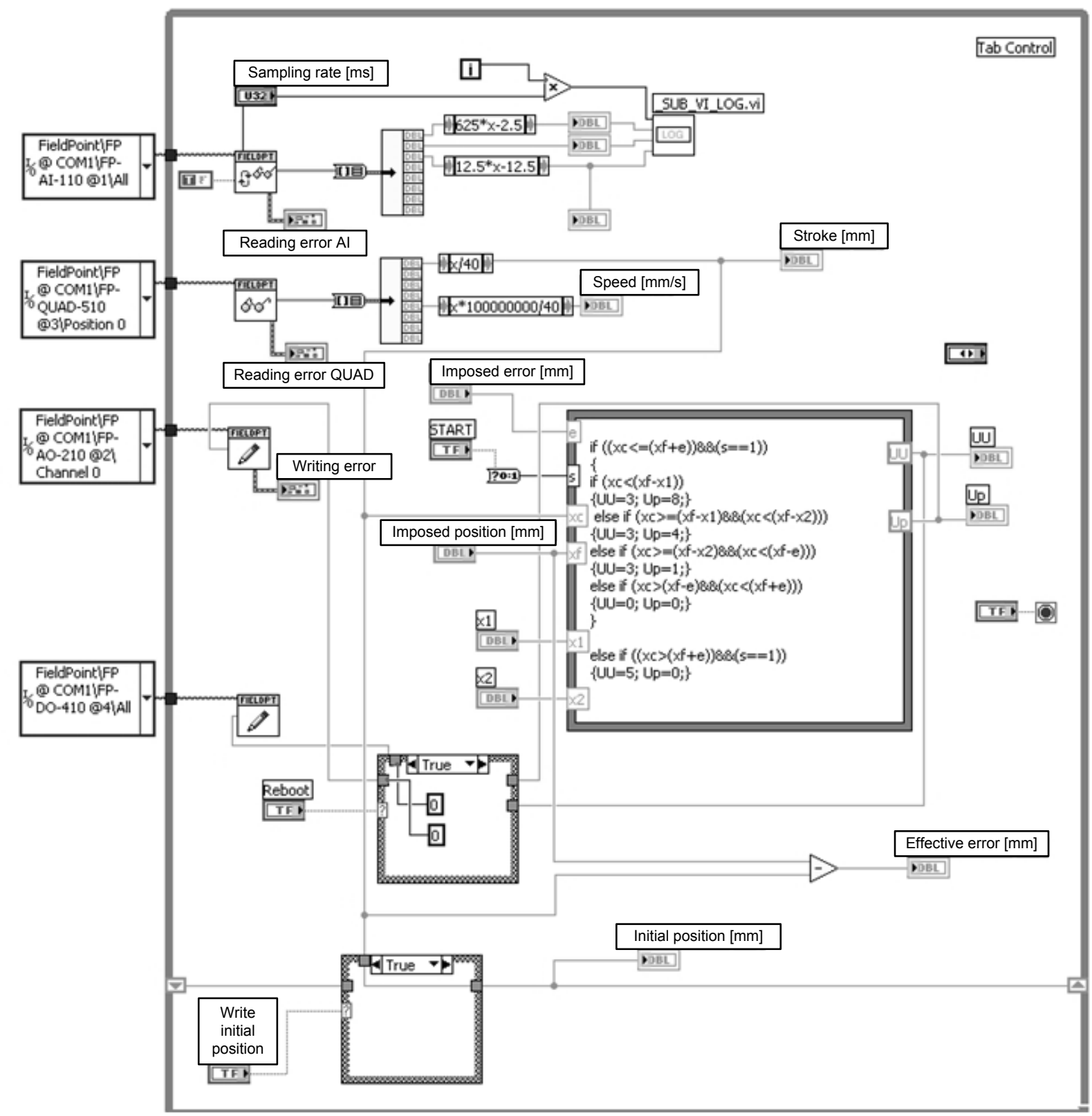

Fig. 13. Programming diagram of the application.

Figure 14 shows the positioning accuracy, defined as $\varepsilon_{r}=y_{p}-y_{r}$, where $\varepsilon_{r}$ is the effective error and $y_{r}$ is the position reached when the programmed final position is $y_{p}$. The pitch of the programmed positions $y_{p}$ was chosen to be $50 \mathrm{~mm}$.

Figure 15 shows the repeatability of the system. Starting from the initial position $y_{i}=10 \mathrm{~mm}$ and programming $y_{f}=390 \mathrm{~mm}$ to be the target position, a positioning error was measured; then $y_{i}$ was programmed to be the target position and the new error was measured. This sequence was repeated for several times.

The dynamic characteristics of the positioning system are presented in figure 16. Starting from the initial position $y_{i}=10 \mathrm{~mm}$ the target position $y_{f}=390 \mathrm{~mm}$ was programmed. The diagrams $y=y(t)$ and $d y / d t$ were found. 


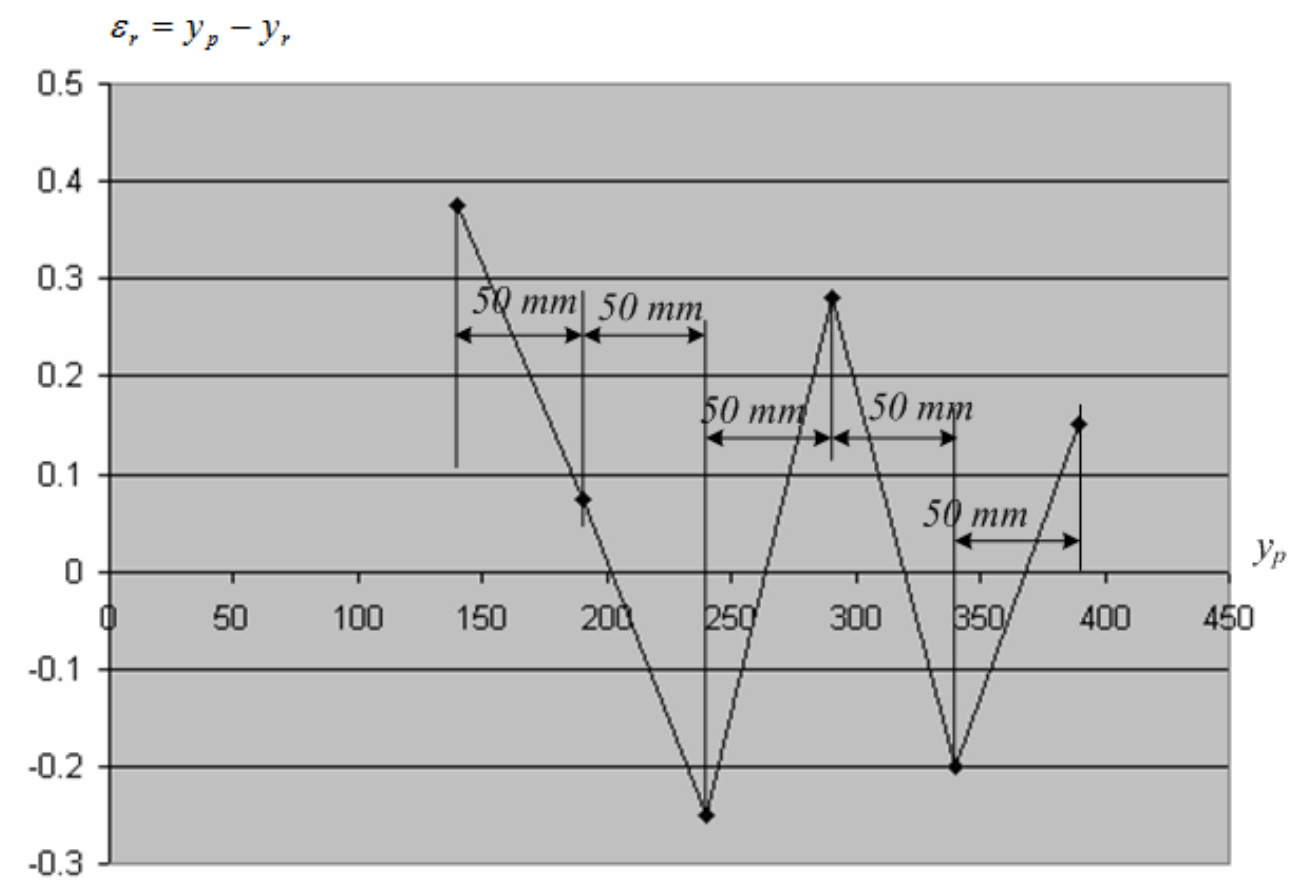

Fig. 14. Positioning accuracy.

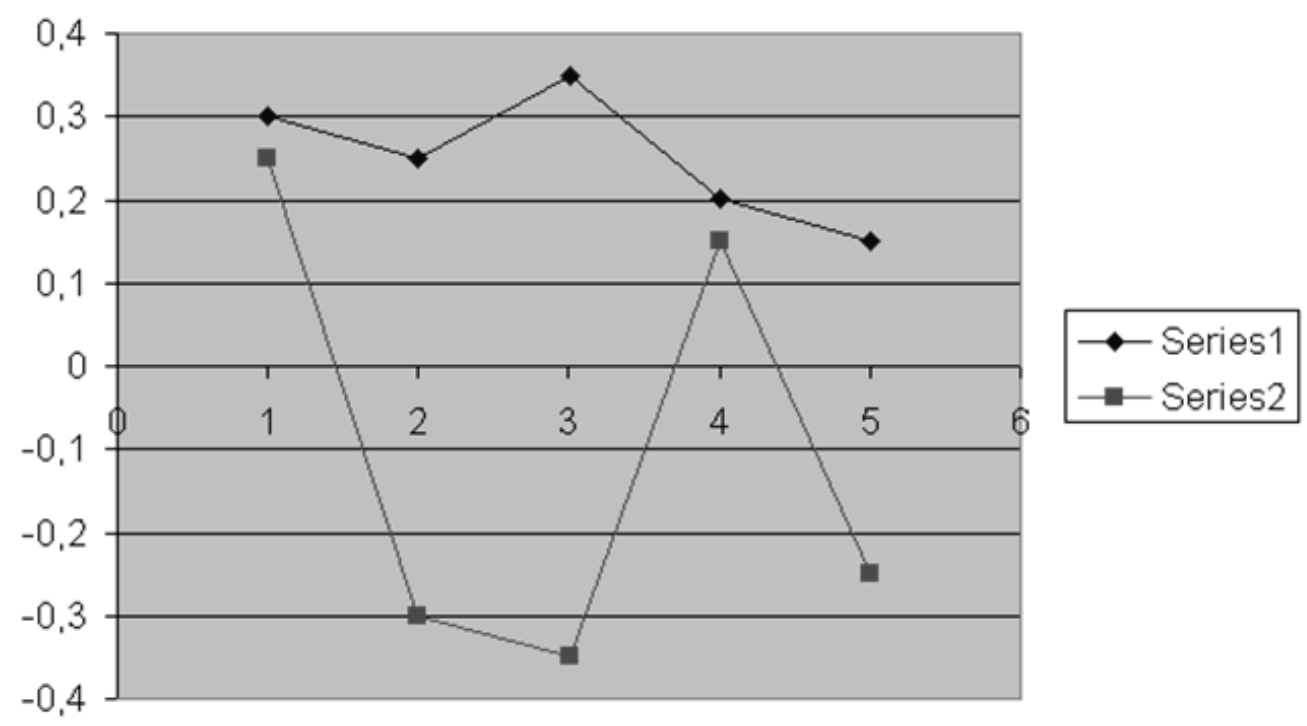

Fig. 15. System repeatability.

\section{Conclusions}

The positioning system presented in the paper can be built by using high quality available commercial products. The "heart" of the system is represented by the proportional pneumatic equipment designed by the authors.

The positioning accuracy is highly dependent on the parameters that define the shape of the control signal profile:

- the initial control voltage applied to the amplifier which drives the piezoelectric actuator must be above a specific level, determined experimentally to be $U_{0}=2 \mathrm{~V}$ ; below this value the system cannot start; 
Avram, M.; Bucsan, C.; Duminica, D.; Bogatu, L. \& Spanu, A.R.: Pneumatic Prop...

- the value of the control voltage in the working stage $U_{r}$ determines the unit response time; this value must be correlated to the programmed displacement; very good results were obtained for $U_{r}=10 \mathrm{~V}$;

The performances of the proportional pneumatic equipment, the quality of the machining of the mechanical structure and the purity of the used working fluid determine the positioning accuracy of the mechatronic unit. The tests performed with the presented positioning system revealed that it is possible to obtain a positioning accuracy of $\pm 0.3 \mathrm{~mm}$.

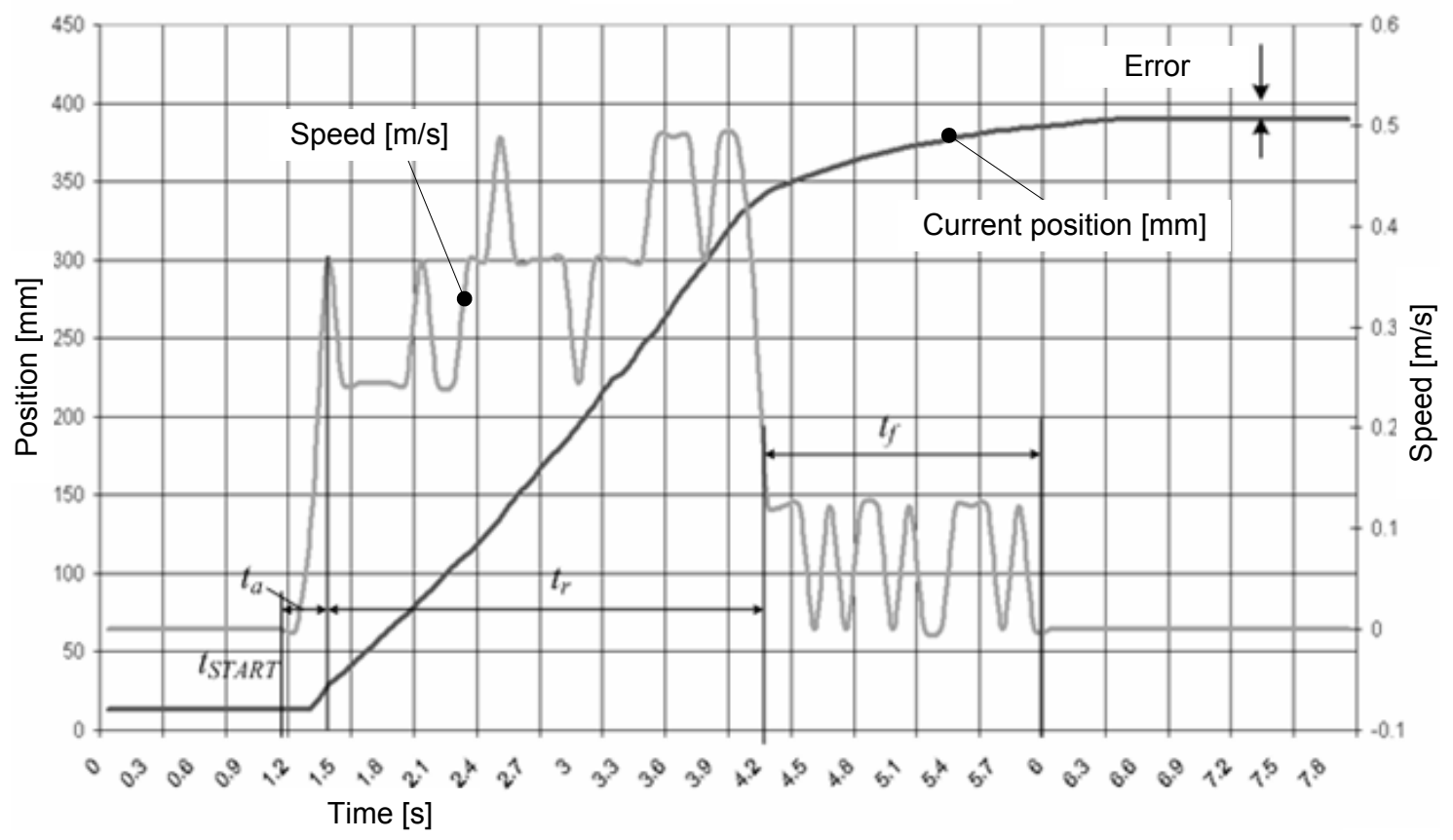

Fig. 16. The driven load position and speed variation $\left(\mathrm{P}_{\text {supply }}=4 \mathrm{bar}, \mathrm{x}_{\max }=390 \mathrm{~mm}\right)$.

\section{References}

Belforte, G.; Bertetto, A.M.; Mazza, L. (1998). Pneumatico - curso completo, Techniche nuove, Milano, 1998

Pashkov, E.; Osinskiz, Y.; Chetviorkin, A. (2004). Electropneumatics in Manufacturing Processes, Isdatelstvo SevNTU, Sevastopol

Avram, M. (2005). Hydraulic and Pneumatic Actuation - Classical and Mechatronic

Equipment and Systems (in Romanian), Editura Universitară, Bucharest , Romania , 2005

Avram, M.; Duminica, D.; Udrea, C.; Gheorghe, V. (2008). Hydronics and

Pneutronics - Applications (in Romanian), Editura Universitara, ISBN 978-

973-749-463-4, Bucharest

*** (2011) www.physikinstrumente.com - Physik Instrumente

*** (2011) www.fieldpoint.net - National Instruments FieldPoint 